\title{
La Investigación En Logística Una Visión Personal
}

Por Luis Francisco López Castro

El acto investigativo es la forma en que el ser humano establece una relación racional con su entorno y le permite cambiarlo y adaptarlo a su propia existencia (no siempre con resultados positivos). Toda actividad que el ser humano realiza es susceptible de ser modificada con el fin de que se adapte mejor a una situación o a unos objetivos determinados, en este orden de ideas el proceso investigativo proporciona una base válida de trabajo al ayudar a contestar los interrogantes básicos: Qué?, Por qué?, Para qué?, etc.

El entorno empresarial no es diferente, aunque en nuestra realidad como país la relación academia-empresa no este muy desarrollada. En un mundo cambiante las corporaciones globales enfrentan el reto de evaluar y configurar sus sistemas y estrategias de producción y distribución mientras buscan reducir costos, servir más que satisfactoriamente a sus clientes y aumentar sus utilidades después de impuestos [1]. Es en este contexto que la logística como área de estudio responde a las necesidades del mundo empresarial, pero en un entorno que evoluciona, la logística también debe hacerlo.

A lo largo y ancho de la geografía mundial corporaciones y universidades a través de sus centros de estudio e investigación estrechan lazos para responder el desafío de la logística global. No es sencillo nombrar todas las áreas y temas tratados en la investigación en logística y esto sería en sí una ardua tarea investigativa. La lista que se presenta a continuación es el resultado de consulta de fuentes bibliográficas y en parte refleja la opinión del autor, es por esto que se debe aclarar al lector que se trata de una visión limitada y subjetiva.

Ya que la preocupación principal es la obtención de utilidades (aumento de ingresos y disminución de costos) aumentando a la vez la satisfacción de los clientes y procurando reducir el impacto negativo sobre el medio ambiente, la investigación en logística se ha enfocado en gran medida 
en el desarrollo de modelos matemáticos que permitan la optimización del uso de los recursos disponibles (tanto físicos como informáticos). Los siguientes son algunos de los temas en que se ha enfocado el esfuerzo investigativo:

- Diseño de redes (Network Design): Se usa para mejorar la cobertura de los servicios y la distribución física. Pueden incluir restricciones variadas como capacidad de los recursos, ventanas de tiempo, flotas no homogéneas, demandas y tiempos estocásticos, rutas no factibles o con dirección, entre otras.

- Programación de operaciones (Scheduling): Trata de la asignación de tareas a recursos, y pueden ir desde la programación de operaciones en manufactura (asignar tareas a máquinas), hasta la asignación de personal (por ejemplo de tripulaciones en aerolíneas) y la gestión de proyectos, entre otras.

Problemas como los mencionados tienen una dificultad implícita, cuando se aumenta su tamaño (cantidad de recursos, actividades, clientes, etc.) incrementa su complejidad computacional y hace que en muchos casos que el tiempo de cálculo necesario para encontrar una respuesta óptima se eleve en razones exponenciales o polinómicas. Es por esto que se ha incrementado el uso de técnicas heurísticas o metaheurísticas para su solución que no garantizan encontrar una respuesta óptima pero si una buena solución en un tiempo razonable. Entre ellas podemos encontrar el Recocido Simulado, Algoritmos Genéticos, Búsqueda Tabú, Optimización por Colonia de Hormigas y Redes Neuronales [2].

Otros temas de investigación en logística son: Sistemas de información que garantizan el procesamiento y la disponibilidad de información a lo largo de la cadena de abastecimiento, Logística inversa y Cadenas Verdes (Green Supply Cahin) que integran la gestión logística con la creciente preocupación del medio ambiente, la gestión de inventarios, la operación de transporte, el diseño de centros de distribución y almacenes, el comercio internacional, entre muchos otros.

Se invita al lector a hacer uso de las fuentes de documentación disponibles tales como bases de datos y revistas especializadas para ahondar en los temas mencionados o en otros que no fueron tenidos en cuenta por el autor. A continuación se ofrecen links relacionados que pueden ser usados para este propósito:

\section{Buscadores de contenido académico:}

- Scirus: http://www.scirus.com/
- Academic Google: http://scholar.google.com.mx/ - Ingenta: http://www.ingentaconnect.com/

Bases de datos: (son de acceso restringido, pero pueden ser consultados en bibliotecas de universidades que tengan programas de maestría y doctorado)

- Sciencedirect - Elsevier: http://www.sciencedirect.com/

- Emerald: http://www.emeraldinsight.com

- ProQuest: http://www.proquest.com/

- Palgrave Macmillan: http://www.palgrave.com/

- Springer: http://springerlink.metapress.com/home/main. $\mathrm{mpx}$

\section{Referencias:}

[1] Goetschalckx, M., Vidal, C., Dogan, C. 2002. Modeling and design of global logistics systems: A review of integrated strategic and tactical models and design algorithms. European Journal of Operations Research 143. $1-18$.

[2] Cordeau, J., Laporte, G., Savelsbergh, M., Vigo, D. 2007. Vehicle Routing. In: Barnhart, C., Laporte, G. (Editors). Handbooks in Operations Research and Management Science. Volume 14. Transportation. NorthHolland Elsevier. Amsterdam. 367 - 428. 